\title{
The requirement for the LysR-type regulator PtrA for Pseudomonas chlororaphis PA23 biocontrol revealed through proteomic and phenotypic analysis
}

Natasha Klaponski', Carrie Selin ${ }^{1}$, Kelly Duke ${ }^{1}$, Vic Spicer ${ }^{2}$, Dilantha WG Fernando ${ }^{3}$, Mark F Belmonte ${ }^{4}$ and Teresa $\mathrm{R}$ de Kievit ${ }^{\text {* }}$

\begin{abstract}
Background: Pseudomonas chlororaphis strain PA23 is a biocontrol agent capable of suppressing the fungal pathogen Sclerotinia sclerotiorum. This bacterium produces the antibiotics phenazine and pyrrolnitrin together with other metabolites believed to contribute to biocontrol. A mutant no longer capable of inhibiting fungal growth was identified harboring a transposon insertion in a gene encoding a LysR-type transcriptional regulator (LTTR), designated ptrA (Pseudomonas transcriptional regulator). Isobaric tag for relative and absolute quantitation (iTRAQ) based protein analysis was used to reveal changes in protein expression patterns in the ptrA mutant compared to the PA23 wild type.

Results: Relative abundance profiles showed 59 differentially-expressed proteins in the ptrA mutant, which could be classified into 16 clusters of orthologous groups (COGs) based on their predicted functions. The largest COG category was the unknown function group, suggesting that many yet-to-be identified proteins are involved in the loss of fungal activity. In the secondary metabolite biosynthesis, transport and catabolism COG, seven proteins associated with phenazine biosynthesis and chitinase production were downregulated in the mutant. Phenotypic assays confirmed the loss of phenazines and chitinase activity. Upregulated proteins included a lipoprotein involved in iron transport, a flagellin and hook-associated protein and four proteins categorized into the translation, ribosome structure and biogenesis COG. Phenotypic analysis revealed that the mutant exhibited increased siderophore production and flagellar motility and an altered growth profile, supporting the proteomic findings.

Conclusion: PtrA is a novel LTTR that is essential for PA23 fungal antagonism. Differential protein expression was observed across 16 COG categories suggesting PtrA is functioning as a global transcriptional regulator. Changes in protein expression were confirmed by phenotypic assays that showed reduced phenazine and chitinase expression, elevated flagellar motility and siderophore production, as well as early entrance into log phase growth.
\end{abstract}

Keywords: Antifungal, Biocontrol, Chitinase, Motility, Phenazine, Pseudomonas, Siderophore, Transcriptional regulator

\footnotetext{
*Correspondence: Teresa.Dekievit@ad.umanitoba.ca

'Department of Microbiology, University of Manitoba, R3T 2N2 Winnipeg, MB, Canada

Full list of author information is available at the end of the article
} 


\section{Background}

Pseudomonas chlororaphis strain PA23 is a biocontrol agent able to protect canola from stem rot disease caused by the fungus Sclerotinia sclerotiorum (Lib.) de Bary [1,2]. This bacterium produces a number of compounds including phenazine 1-carboxylic acid (PCA), 2-hydroxyphenazine (2$\mathrm{OH}-\mathrm{PHZ}$ ), pyrrolnitrin, protease, lipase, chitinase and siderophores, some of which have been shown to contribute to fungal antagonism [3-5]. Public concern over the use of chemical pesticides together with the potential for acquiring resistance to these compounds has led to renewed interest in bacterial antagonists, such as PA23, for biocontrol. Despite demonstrating excellent disease control in the greenhouse, many biocontrol agents suffer from inconsistent performance in the field [6-8]. Poor field performance is likely due, at least in part, to variable expression of genes and gene products required for disease suppression. It is essential, therefore, to elucidate the molecular mechanisms mediating PA23 biocontrol so that production of the pathogen-suppressing factor (s) can be optimized in the environment.

In Pseudomonas spp. that act as biocontrol agents, expression of disease-suppressive metabolites is controlled by a multi-tiered network of regulation. One of the key regulatory elements is the GacS/GacA two-component signal transduction system, comprised of the sensor kinase GacS and its cognate response regulator GacA [9]. In many pseudomonads, including PA23, a mutation in gacS or gacA leads to a loss of fungal antagonism [4,9]. Working in concert with $\mathrm{GacS} / \mathrm{GacA}$ is the Rsm system which consists of RsmA-like repressor proteins and untranslated regulatory RNAs. The repressor proteins act post-transcriptionally by binding to the ribosomebinding site (RBS) in target mRNA [10]. The regulatory RNAs antagonize repression by titrating out the RsmA-like proteins, rendering the RBS of target genes accessible to the translational machinery [10]. Additional regulatory elements that oversee production of PA23 antifungal metabolites include the PhzR/PhzI quorum-sensing (QS) circuit [11], the stationary phase sigma factor RpoS [12], a regulator of RpoS called PsrA [13], and a global stress response system known as the stringent response [12]. Substantial interaction occurs between the regulators themselves, which adds to the complexity of the regulatory hierarchy [11-13].

Through transposon mutagenesis, a PA23 mutant was identified that exhibited a complete loss of antifungal activity, similar to what is observed for a gac mutant $[4,13]$. Sequence analysis revealed that the interrupted gene, designated ptrA (Pseudomonas transcriptional regulator), encodes a protein belonging to the LysR-type transcriptional regulator (LTTR) family. LTTRs can act as either activators or repressors and are known to control a diverse range of metabolic functions including cell invasion and virulence, QS, oxidative stress, and amino acid metabolism [14]. Given the remarkably complex regulatory network that oversees the production of antifungal compounds, the aim of the current study was to understand the global impact of the ptrA mutation on PA23 protein expression. Using the isobaric tag for relative and absolute quantitation (iTRAQ) technique, 59 proteins were found to be differentially expressed in the ptrA mutant compared to the wild type. Changes in protein expression were confirmed by phenotypic assays that showed reduced phenazine and chitinase expression, elevated flagellar motility and siderophore production, as well as early entrance into the logarithmic growth phase.

\section{Results and discussion}

Isolation of a Pseudomonas chlororaphis PA23 mutant deficient in antifungal activity

Approximately 4000 transconjugants were screened in radial diffusion plate assays to identify mutants displaying

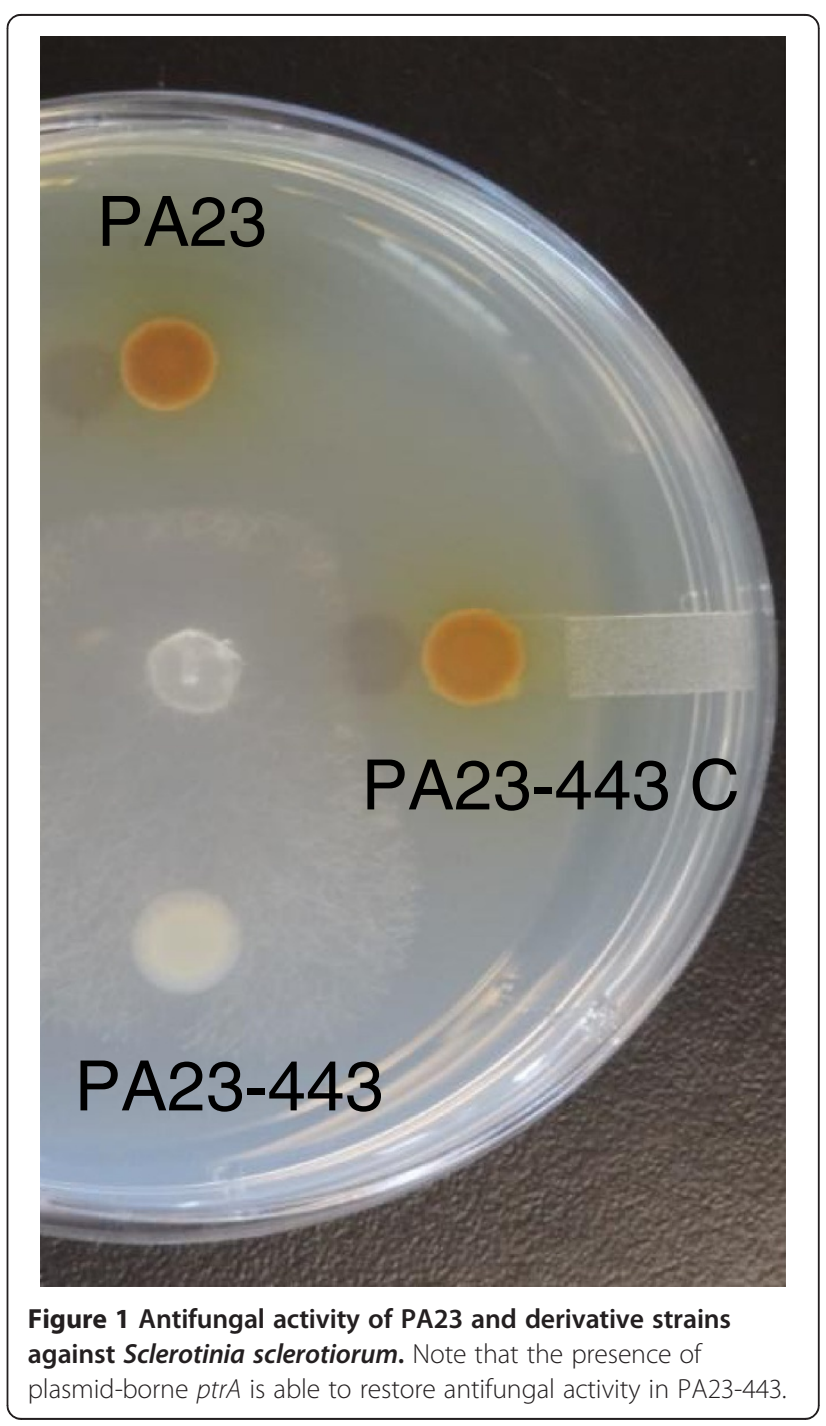


increased or decreased antifungal activity compared to the wild type. One mutant was identified, PA23-443, that exhibited no antifungal activity and was white in colour, indicating a loss of phenazine production [5] (Figures 1 and 2B). DNA flanking the Tn exhibited $89 \%$ identity at the amino acid level to a Pseudomonas fluorescens LTTR [Genbank: AAY90576]. The newly identified gene was designated ptrA. To verify that the phenotype of PA23-443 was due to ptrA inactivation, the ptrA gene was PCR amplified and cloned into pUCP22 for complementation. The presence of pUCP22-ptrA restored antifungal activity to that of the wild type (Figure 1).

Sequence analysis revealed that the site of Tn insertion lies $803 \mathrm{bp}$ downstream of the PtrA translational start (data not shown), which is predicted to disrupt the co-inducer recognition/response domain [15]. Previous studies of the LTTRs NodD and NahR revealed that mutations in this region result in a co-inducer-independent phenotype which affects DNA binding and thus the activation/repression properties of the proteins [14,15]. Directly downstream of $p \operatorname{tr} A$ but in the opposite orientation lies a gene encoding a protein that is $99 \%$ identical at the amino acid level to a DoxX-family protein found in P. chlororaphis subsp. aurantiaca PB-St2 [Genbank accession \#WP_023968058]. Based on sequence similarity, DoxX could be involved in pathways related to elemental sulfur oxidation [16]. Immediately upstream of $p \operatorname{tr} A$, in the opposite orientation, lies a gene encoding a shortchain dehydrogenase $(s c d)$. Short-chain dehydrogenases are part of a superfamily of enzymes designated as the $\mathrm{NAD}(\mathrm{H})$ - or NADP(H)-dependent short-chain dehydrogenases/reductases (SDRs). The SDRs comprise a very large grouping of biologically important proteins found in virtually all forms of life [17]. At present, it is unclear whether the genes upstream and downstream of $p t r A$ play a role in regulation.

Through blastn analysis, ptrA homologs were found within the genomes of several Pseudomonas species, with the highest degree of nucleotide identity exhibited by Pseudomonas sp. UW4 (85\%), followed by Pseudomonas protegens strains Pf-5 (84.7\%) and CHA0 (84.7\%), Pseudomonas fluorescens strains Pf0-1 (84.5\%) and F113 (82.5\%), Pseudomonas brassicacearum subsp. brassicacearum NFM421 (82.4\%), Pseudomonas poae RE*1-1-14 (79.3\%), and Pseudomonas resinovorans NBRC 106553 (76.1\%) [18]. Collectively, our findings indicate that PtrA is a newly identified regulator of PA23 biocontrol, and homologs of this regulator are present in a number of Pseudomonas species.

\section{Differential protein expression between the PA23 wild type and the ptrA mutant}

PtrA belongs to the LTTR family, which is the largest known family of prokaryotic DNA binding proteins [14].

A
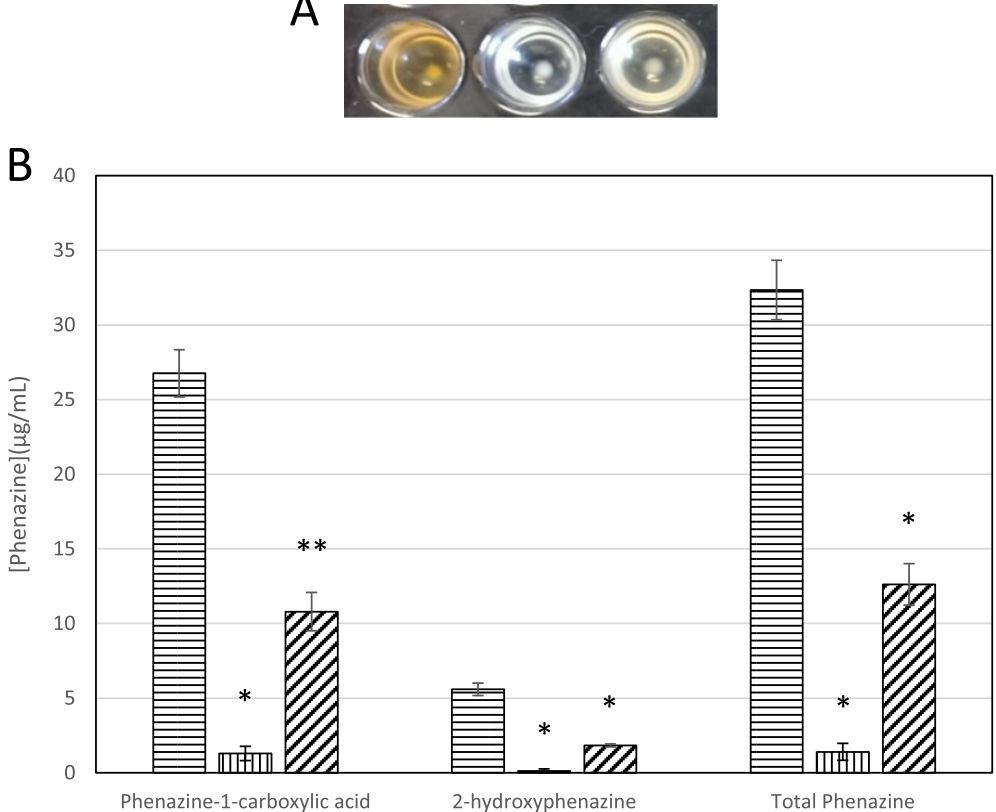

Figure 2 Phenazine production in PA23, PA23-443, and PA23-443 harboring ptrA in trans. Panel A. Color development of overnight cultures grown in $\mathrm{M} 9$ minimal media supplemented with $1 \mathrm{~mm} \mathrm{MgSO}$ and $0.2 \%$ glucose. Left to right; PA23 (pUCP22), PA23-443 (pUCP22), PA23-443 (ptrA-pUCP22). Panel B. Quantitative phenazine analysis of cells grown in M9 minimal media supplemented with $1 \mathrm{~mm} \mathrm{MgSO}_{4}$ and $0.2 \%$ glucose. Horizontal lines; PA23 (pUCP22), vertical lines; PA23-443 (pUCP22), diagonal lines; PA23-443 (ptrA-pUCP22). Total phenazine: phenazine-1-carboxylic acid + 2-hydroxy-phenazine. *; $P<0.0001$, **; $p<0.0002$. 
Table 1 Differentially expressed proteins in mutant PA23-443 compared to the PA23 wild type

\begin{tabular}{|c|c|c|c|c|}
\hline COG Category & Locus Tag & Predicted Function & Fold Change $^{a}$ & $\mathrm{~V}_{\text {diff }}$ Score \\
\hline \multirow[t]{3}{*}{ Amino acid transport and metabolism } & MOK_00491 & $\begin{array}{l}\text { 4-aminobutyrate aminotransferase } \\
\text { and related aminotransferases }\end{array}$ & 1.59 & 2.24 \\
\hline & MOK_03651 & Monoamine oxidase & -2.39 & -2.7 \\
\hline & MOK_04019 & ornithine carbamoyltransferase & -1.48 & -1.67 \\
\hline Nucleotide transport and metabolism & MOK_04929 & hypothetical protein & -3.13 & -2.54 \\
\hline \multirow[t]{3}{*}{ Carbohydrate transport and metabolism } & MOK_03378 & Chitinase & -3.30 & -3.76 \\
\hline & MOK_05029 & Glucose/sorbosone dehydrogenases & -1.68 & -2.04 \\
\hline & MOK_05478 & Chitinase & -2.61 & -1.66 \\
\hline Lipid transport and metabolism & MOK_04573 & Acyl dehydratase & -2.16 & -2.42 \\
\hline \multirow[t]{4}{*}{ Translation, ribosomal structure and biogenesis } & MOK_00565 & $\begin{array}{l}\text { Translation elongation factor } \mathrm{P}(\mathrm{EF}-\mathrm{P}) / \\
\text { translation initiation factor } 5 \mathrm{~A}(\mathrm{elF}-5 \mathrm{~A})\end{array}$ & 1.61 & 1.94 \\
\hline & MOK_01324 & ribosomal protein L32 & 2.33 & 2.77 \\
\hline & MOK_02337 & $\begin{array}{l}\text { aspartyl/glutamyl-tRNA(Asn/Gln) } \\
\text { amidotransferase, C subunit }\end{array}$ & 2.09 & 1.7 \\
\hline & MOK_04471 & ribosomal protein S19, bacterial/organelle & 1.49 & 1.7 \\
\hline \multirow[t]{3}{*}{ Transcription } & MOK_02056 & cold shock domain protein CspD & -2.31 & -1.81 \\
\hline & MOK_02888 & Cold shock proteins & 2.30 & 2.44 \\
\hline & MOK_03359 & Cold shock proteins & 1.26 & 1.65 \\
\hline Replication, recombination and repair & MOK_00606 & $\begin{array}{l}\text { competence protein ComEA helix-hairpin-helix } \\
\text { repeat region }\end{array}$ & -2.78 & -3.04 \\
\hline Cell wall, membrane and envelope biogenesis & MOK_05137 & $\begin{array}{l}\text { Outer membrane protein and related } \\
\text { peptidoglycan-associated (lipo)proteins }\end{array}$ & -1.65 & -1.79 \\
\hline Cell motility & MOK_01499 & Flagellin and related hook-associated proteins & 2.71 & 3.26 \\
\hline \multirow{4}{*}{$\begin{array}{l}\text { Post-translational modification, protein turnover } \\
\text { and chaperones }\end{array}$} & MOK_00750 & monothiol glutaredoxin, Grx4 family & 1.20 & 1.81 \\
\hline & MOK_01830 & peroxiredoxin, OsmC subfamily & -2.61 & -2.69 \\
\hline & MOK_05742 & Peroxiredoxin & -1.84 & -1.78 \\
\hline & MOK_05953 & $\begin{array}{l}\text { Peptidyl-prolyl cis-trans isomerase (rotamase) - } \\
\text { cyclophilin family }\end{array}$ & 2.00 & 1.73 \\
\hline Inorganic ion transport and metabolism & MOK_05447 & $\begin{array}{l}\text { Predicted periplasmic lipoprotein involved in } \\
\text { iron transport }\end{array}$ & 1.42 & 1.73 \\
\hline \multirow{5}{*}{$\begin{array}{l}\text { Secondary metabolites biosynthesis, transport } \\
\text { and catabolism }\end{array}$} & MOK_01048 & Phenazine biosynthesis protein A/B. & -4.22 & -4.58 \\
\hline & MOK_01049 & Phenazine biosynthesis protein A/B. & -3.25 & -4.26 \\
\hline & MOK_01053 & phenazine biosynthesis protein PhzF family & -1.19 & -2.1 \\
\hline & MOK_01054 & Pyridoxamine-phosphate oxidase & -1.25 & -2.18 \\
\hline & MOK_01055 & Aromatic ring hydroxylase & -2.45 & -2.43 \\
\hline \multirow[t]{4}{*}{ General function prediction only } & MOK_01152 & Predicted periplasmic or secreted lipoprotein & -2.29 & -2.42 \\
\hline & MOK_02985 & intracellular protease, Pfpl family & 1.67 & 1.93 \\
\hline & MOK_03813 & Predicted O-methyltransferase & -2.12 & -1.73 \\
\hline & MOK_05714 & Serine protease inhibitor ecotin & -1.33 & -1.65 \\
\hline \multirow[t]{6}{*}{ Function unknown } & MOK_00258 & Protein of unknown function (DUF3313). & -1.81 & -2.03 \\
\hline & MOK_00808 & hypothetical protein & -8.28 & -7.73 \\
\hline & MOK_01097 & hypothetical protein & -2.10 & -2.22 \\
\hline & MOK_01302 & hypothetical protein & -1.32 & -2.08 \\
\hline & MOK_01398 & hypothetical protein & -2.04 & -2.19 \\
\hline & MOK_01832 & Protein of unknown function (DUF1161). & -1.14 & -1.94 \\
\hline
\end{tabular}




\begin{tabular}{|c|c|c|c|c|}
\hline & MOK_02425 & $\begin{array}{l}\text { Sigma } 54 \text { modulation protein/S30EA ribosomal } \\
\text { protein. }\end{array}$ & 1.36 & 2.22 \\
\hline & MOK_02468 & $\begin{array}{l}\text { poly(hydroxyalkanoate) granule-associated } \\
\text { protein }\end{array}$ & -2.70 & -3.66 \\
\hline & MOK_02469 & $\begin{array}{l}\text { poly(hydroxyalkanoate) granule-associated } \\
\text { protein }\end{array}$ & -1.75 & -2.32 \\
\hline & MOK_03057 & Uncharacterized protein conserved in bacteria & -1.86 & -2.29 \\
\hline & MOK_03064 & type VI secretion protein, VC_A0107 family & -2.87 & -3.14 \\
\hline & MOK_03065 & type VI secretion protein, EvpB/NC_A0108 family & -2.72 & -3.02 \\
\hline & MOK_03231 & outer membrane porin, OprD family. & 1.49 & 1.8 \\
\hline & MOK_03379 & Uncharacterized protein conserved in bacteria & -4.52 & -5.06 \\
\hline & MOK_03717 & hypothetical protein & -5.36 & -6.81 \\
\hline & MOK_03859 & hypothetical protein & -2.60 & -2.27 \\
\hline & MOK_04005 & Protein of unknown function (DUF3613). & -2.39 & -2.06 \\
\hline & MOK_04318 & Predicted integral membrane protein & -1.80 & -2.21 \\
\hline & MOK_04378 & $\begin{array}{l}\text { Putative phospholipid-binding domain./LysM } \\
\text { domain. }\end{array}$ & -2.22 & -3.47 \\
\hline & MOK_04746 & hypothetical protein & -2.29 & -2.71 \\
\hline & MOK_04755 & hypothetical protein & -3.36 & -3.84 \\
\hline & MOK_05477 & Uncharacterized protein conserved in bacteria & -2.09 & -1.41 \\
\hline & MOK_05648 & hypothetical protein & -4.51 & -4.7 \\
\hline & MOK_05758 & hypothetical protein & -4.00 & -4.19 \\
\hline & MOK_06084 & Iron-sulfur cluster assembly accessory protein & 1.72 & 1.73 \\
\hline & MOK_06136 & hypothetical protein & -5.20 & -5.37 \\
\hline Signal transduction mechanisms & MOK_04087 & Putative Ser protein kinase & -1.38 & -2.06 \\
\hline
\end{tabular}

Proteins with $V_{\text {diff }} \geq+1.65$ or $V_{\text {diff }} \leq-1.65$, corresponding to proteins expressed in the upper or lower $5 \%$ of the population distribution are shown.

${ }^{a} \log _{2}\left(\operatorname{tag}_{115} / \operatorname{tag}_{117}\right)$.

LTTRs can function as either repressors or activators for single or operonic genes. Furthermore, these regulators may be divergently transcribed from their target genes or may control expression of numerous genes scattered about the chromosome [14]. In PA23, expression of antifungal metabolites is governed by a complex network of regulatory elements and substantial interaction occurs between the regulators themselves [4,11-13]. To understand the global impact of the ptrA mutation on PA23 physiology, iTRAQ proteomic analysis was carried out to reveal proteins that were differentially expressed between the PA23 wild type and the ptrA mutant. A total of 771 proteins were matched to proteins found within the $P$. chlororaphis gp72 reference genome [19]. Fifty nine of these proteins were differentially expressed between the two strains, exhibiting a vector difference $\left(V_{\text {diff }}\right)$ greater than or equal to +1.65 and less than or equal to -1.65 , corresponding to proteins in the upper or lower $10 \%$ of the population distribution (Table 1 ). The 59 proteins could be classified into 16 clusters of orthologous groups (COGs) based on their predicted function. Figure 3 summarizes the classification of the identified proteins, indicating significant up- or downregulation of protein expression. The largest COG category was the unknown function group, suggesting that many yet-to-be-identified proteins play a role in the loss of biocontrol exhibited by PA23-443.

\section{PtrA regulates phenazine production in PA23}

The secondary metabolite biosynthesis, transport and catabolism COG category represented the next largest grouping (Table 1). Initially, two of the proteins (MOK_01048, MOK_01053) were classified under the general function category and one protein (MOK_01054) was categorized under the transport and metabolism grouping. Upon further investigation, the locus tags indicated that they are part of the phenazine biosynthetic operon, leading to their reclassification into the secondary metabolite biosynthesis COG.

The phenazine operon has been well characterized in many pseudomonads, with phzABCDEFG comprising the core biosynthetic locus [20]. In this study, proteins with locus tags MOK_01048 and MOK_01049, identified as phenazine biosynthesis protein $A / B$, were significantly 
downregulated (Table 1). All phenazine-producing pseudomonads have an adjacent and nearly identical copy of the $p h z B$ gene, termed $p h z A$ [20]. PhzA catalyzes the condensation reaction of two ketone molecules in the phenazine biosynthesis pathway [20]. PhzF (identified as MOK_01053 in this study) works as an isomerase, converting trans-2,3-dihydro-3-hydroxyanthranilic acid (DHHA) into 6-amino-5-oxocyclohex-2-ene-1-carboxylic acid prior to the condensation reaction catalyzed by the PhzA/B proteins [20]. phzG encodes an FMNdependent pyridoxamine oxidase (identified as MOK_01054 in this study), which is hypothesized to catalyze the conversion of DHHA to 5,10-Dihydro-PCA [21]. In some pseudomonads, genes downstream of the core biosynthetic operon are required for generation of phenazine derivatives [22-24]. In P. chlororaphis 30-84, for example, $p h z O$ lies downstream of the core operon; $\mathrm{PhzO}$ is an aromatic hydroxylase that catalyzes the conversion of PCA into 2-OH-PHZ [23]. More recently, in $P$. chlororaphis gp72, the $p h z O$ gene was shown to convert PCA into 2-OH-PHZ through a 2-OH-PCA intermediate [25]. Like other P. chlororaphis strains, PA23 produces 2-OH-PHZ and we believe the downregulated aromatic ring hydroxylase (MOK_01055) is PhzO. Therefore, in the absence of a functional ptrA gene, four of the core phenazine biosynthetic enzymes (PhzA, PhzB, $\mathrm{PhzF}, \mathrm{PhzG}$ ) and one aromatic ring hydroxylase (PhzO) are significantly downregulated. The fact that PtrA plays a critical role in regulating $p h z$ expression was not surprising considering the lack of orange pigment produced by the ptrA mutant (Figures 1 and 2A). Reduced phenazine expression was further substantiated by quantitative assays. As illustrated in Figure 2B, there is a 15-fold decrease in phenazine production in PA23-443 compared to the PA23 wild type. When ptrA was expressed in trans, some restoration of phenazine production was achieved.

\section{Chitinase production is under PtrA control}

Our iTRAQ proteomic results showed that two chitinase enzymes (MOK_03378 and MOK_05478) were significantly downregulated in the PA23-443 mutant (Table 1). These results were supported by chitinase assays, which

Table 2 Chitinase activity of $\boldsymbol{P}$. chlororaphis strain PA23 and derivative strains

\begin{tabular}{|c|c|c|}
\hline \multirow[t]{2}{*}{ Strain } & \multicolumn{2}{|c|}{ 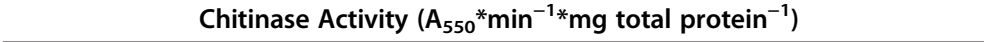 } \\
\hline & Early stationary phase $^{a}$ & Late stationary phase $^{a}$ \\
\hline PA23 (pUCP22) & $0.11(0.03)$ & $0.12(0.004)$ \\
\hline PA23-443 (pUCP22) & $0.0(0.0)^{b}$ & $0.0(0.0)^{c}$ \\
\hline PA23-443 (ptrA-pUCP22) & $0.10(0.03)^{d}$ & $0.11(0.01)^{\mathrm{e}}$ \\
\hline
\end{tabular}

${ }^{a}$ Mean (standard deviation) of enzyme activity of three replicates.

${ }^{\mathrm{b}}$ Significantly different from wild type $(\mathrm{P}<0.005)$.

cSignificantly different from wild type $(P<0.0001)$.

${ }^{d}$ Not significantly different from wild type.

${ }^{\text {e}}$ Significantly different from wild type $(P<0.05)$. 
Table 3 Siderophore production by $P$. chlororaphis PA23, PA23-443 and PA23-443 harboring ptrA in trans

\begin{tabular}{lc}
\hline Strain & Zone of orange halo \\
\hline PA23 (pUCP22) & $0.5(0.0)$ \\
PA23-443 (pUCP22) & $1.6(0.2)^{b}$ \\
PA23-443 (ptrA-pUCP22) & $0.6(0.2)^{c}$ \\
\hline
\end{tabular}

${ }^{a}$ Mean (standard deviation) of orange haloes $(\mathrm{mm})$ surrounding colonies on CAS agar. Five replicates were examined.

${ }^{b}$ Significantly different from the wild type $(p<0.0001)$.

${ }^{c}$ Not significantly different from the wild type.

clearly indicated no detectable enzyme activity in the $p t r A$ mutant (Table 2). Addition of plasmid-borne ptrA elevated chitinase activity close to that of the wild type (Table 2). Collectively our findings indicate that $p t r A$ is necessary for chitinase production. The LTTR, ChiR, has been previously shown to indirectly regulate all chitinases produced in Serratia marcescens 2170 [26]. Proteomic analysis of a $P$. aeruginosa gacA mutant revealed that chitinase (ChiC) and a chitin-binding protein $(\mathrm{CbpD})$ were decreased 8-fold and 2.2-fold respectively, as compared to the wild type [27].

\section{Siderophore production is upregulated in PA23-443 com-} pared to the PA23 wild type

In the ptrA mutant, a lipoprotein involved in iron transport (MOK_05447) was found to be significantly upregulated (Table 3). This finding prompted us to explore whether the mutant exhibited elevated siderophore expression. Siderophores are thought to contribute to biocontrol by sequestering iron, thereby restricting pathogen growth. Following 24 hours growth on CAS agar plates, mutant PA23-443 showed a 3-fold increase in the size of the orange halo surrounding the colony, indicating increased siderophore production compared to the wild type (Table 3). As expected, overexpression of ptrA restored the wild-type phenotype. Since the ptrA mutant expresses significantly increased levels of siderophore but exhibits a complete loss of antifungal activity, it is clear that elevated siderophore expression alone is not sufficient for S. sclerotiorum control.

\section{Loss of ptrA results in early entry into stationary phase}

We observed significant upregulation of proteins involved in translation, ribosomal structure and biogenesis in the ptrA mutant (Table 1). These proteins include a translation elongation factor (MOK_00565), a tRNA amidotransferase (MOK_02337) and ribosomal proteins L32 and S19 (MOK_01324 and MOK_04471, respectively) which make up structural components of both the large and small ribosomal subunits of the 705 ribonucleoprotein complex [28] (Table 1). To determine whether PA23-443 exhibited an altered pattern of growth compared to the wild type, growth rate analysis was undertaken. As depicted in Figure 4, the mutant enters the logarithmic (log) growth phase around hour 8, which starts to plateau by hour 13 . Conversely, the PA23 wild type does not enter log phase until hour 11, ending with entrance into early stationary phase at 19 hours of growth. Another interesting difference observed was the maximum population density achieved. The PA23 wild type consistently reached a higher $\mathrm{OD}_{600}$ in stationary phase compared to PA23-443 (Figure 4). A similar altered pattern of growth has been observed for gacS mutants of PA23 and 30-84 which exhibit a shorter lag phase and earlier entry into logarithmic growth phase $[4,29]$. LTTRs have previously been implicated in the regulation of cellular growth factors. For example, the well-studied LTTR OxyR is involved in regulating the expression of various metabolic genes such as tRNA nucleotidyl transferases and synthetases, ribosomal proteins and QS-regulated targets [30].

\section{PtrA negatively affects motility}

Our iTRAQ proteomic data indicated upregulation of the flagellin and related hook-associated protein (MOK_01499)

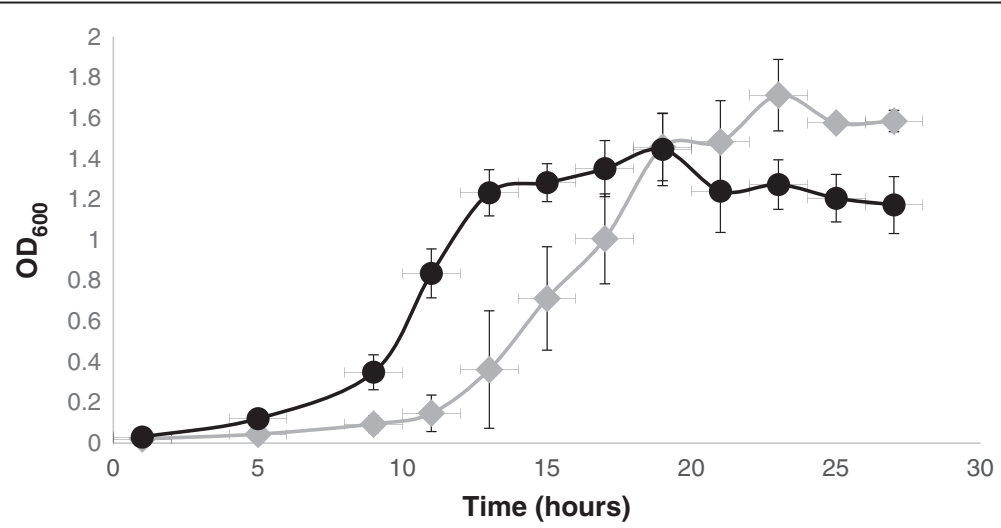

Figure 4 Growth rate analysis of wild-type PA23 and mutant PA23-443. Cells were grown in M9 minimal media supplemented with 1 mM $\mathrm{MgSO}_{4}$ and $0.2 \%$ glucose. Spectrophotometric optical densities were taken at $600 \mathrm{~nm}$. Diamonds; PA23wt, circles; PA23-443. 
in PA23-443. Further inspection of the locus tags upstream of MOK_01499 also indicated upregulation of proteins FliG (MOK_01489; $\left.\mathrm{V}_{\text {diff }}=+0.72\right)$ and FliS (MOK_01496; $\mathrm{V}_{\text {diff }}=+0.66$ ), although this upregulation was not considered significant. The upregulated flagellin and related hook-associated protein, therefore, is likely part of the Fli operon based on its proximity to upstream genes. To verify the results of the proteomic analysis, motility assays were conducted. As outlined in Table 4, swimming (flagellar) motility was almost 3-fold greater in PA23-443 compared to the wild type, indicating that PtrA is having a repressive effect on this phenotype. In a similar fashion, proteomic analysis of a $P$. aeruginosa gacA mutant revealed a 7.5-fold and 8.8fold increase in expression of a flagellin (FliC) and flagellar-capping protein (FliD), respectively [27]. Introduction of ptrA in trans caused a modest reduction in motility, but did not fully restore the wild-type phenotype. It is important to bear in mind that for our complementation studies, multiple copies of the ptrA gene were provided rather than a single chromosomal copy. Because LTTRs bind both activation binding sites and regulatory binding sites upstream of target genes [14], the number of copies of the regulator may be of critical importance for proper binding and subsequent regulation of target genes. This observation was noted with complementation studies involving the LTTR OxyR in restoration of rhamnolipid and pyocyanin production in $P$. aeruginosa [31]. When multiple copies of $o x y R$ were present in the cell, the wildtype phenotype was not restored; whereas insertion of single chromosomal copy of the LTTR gene resulted in full complementation [31].

\section{PtrA regulates pyrrolnitrin production in PA23}

Based on ITRAQ analysis, a tryptophan halogenase (MOK_04031) was identified under the amino acid transport and metabolism COG category, but was not significantly differentially expressed in the ptrA mutant $\left(\mathrm{V}_{\text {diff }}=-0.24\right)$. At locus tag MOK_04033, another chlorinating halogenase was identified in the $P$. chlororaphis gp72 genome, but was not differentially expressed in the ptrA mutant. These enzymes are likely prnA and prnC, forming part of the prnABCD pyrrolnitrin biosynthetic operon [32]. Subsequent pyrrolnitrin quantification via HPLC analysis revealed that wild type PA23 produced

Table 4 Motility analysis of $\boldsymbol{P}$. chlororaphis strain PA23, PA23-443 and PA23-443 harboring ptrA in trans

\begin{tabular}{lc}
\hline Strain & Motility zone diameter $(\mathbf{m m})$ at $\mathbf{4 8} \mathbf{~ h}^{\mathbf{a}}$ \\
\hline PA23 (pUCP22) & $17.0(0.0)$ \\
PA23-443 (pUCP22) & $47.5(0.6)^{\mathrm{b}}$ \\
PA23-443 (ptrA-pUCP22) & $43.8(1.6)^{\mathrm{b}}$ \\
\hline
\end{tabular}

${ }^{a}$ Mean (standard deviation) of swim zones from four replicates.

${ }^{b}$ Significantly different from the wild type $(p<0.0001)$. an average of $3.48( \pm 0.45) \mu \mathrm{g}$ of pyrrolnitrin, whereas in the ptrA mutant, no pyrrolnitrin was detected. However, when ptrA was expressed in trans in PA23-443, pyrrolnitrin production was restored to wild-type levels (3.90 \pm $0.20 \mu \mathrm{g})$. Significant downregulation of pyrrolnitrin expression may not have been identified through iTRAQ analysis as cell samples were taken at the onset of stationary phase. To obtain enough pyrrolnitrin for quantification, cell culture extracts are routinely performed after five days of growth [5]. Thus, there may have been differences in protein expression in late stationary phase that were not detected in our iTRAQ analysis. As pyrrolnitrin has previously been reported as essential for PA23 biocontrol [5], the lack of pyrrolnitrin production by the ptrA mutant is likely a major contributor to the loss of antifungal activity.

\section{Conclusions}

In the present study, we describe the characterization of a PA23 derivative with a mutation in a gene encoding a novel transcriptional regulator, designated PtrA. As the mutant is no longer capable of suppressing the fungal pathogen S. sclerotiorum, PtrA is essential for PA23 biocontrol. It is apparent that PtrA affects many facets of PA23 physiology. Differential protein expression was observed across 16 different COG categories, indicating that PtrA is likely acting as a global transcriptional regulator. One of the limitations associated with this study stems from the fact that our proteomic analysis was based on the $P$. chlororaphis gp72 reference genome. In the future, the availability of the PA23 genome sequence may allow us to better understand the function of these differentially expressed proteins. In addition, several aspects of PtrA regulation have yet to be revealed, for example, LTTRs are frequently autoregulated and coinducer molecules profoundly impact binding specificity [15]. We are currently investigating the DNA targets of PtrA transcriptional regulation, including $p t r A$ itself. Furthermore, the nature of the PtrA effector and its role in binding has yet to be discovered. It is hoped that by unraveling the complex regulatory hierarchy overseeing production of antifungal compounds, this bacterium can be used in a consistent and predictable manner for suppression of S. sclerotiorum in the field.

\section{Methods}

\section{Bacterial strains and growth conditions}

The bacterial strains and plasmids used in this study are listed in Table 5. Escherichia coli strains were cultured at $37^{\circ} \mathrm{C}$ on Lennox Luria Bertani (LB) agar (Difco Laboratories, Detroit, Michigan). P. chlororaphis PA23 and its derivatives were cultured at $28^{\circ} \mathrm{C}$ on LB agar or M9 minimal media supplemented with $1 \mathrm{mM} \mathrm{MgSO}_{4}$ and $0.2 \%$ glucose. For antifungal assays, bacteria were grown on 
Table 5 Bacterial strains, plasmids and primers used in this study

\begin{tabular}{|c|c|c|}
\hline Strain/plasmid/primer & Relevant genotype or phenotype & Source or reference \\
\hline P. chlororaphis PA23 & $\mathrm{Phz}^{+} \mathrm{Rif}^{\mathrm{R}}$ wild type (soybean plant isolate) & {$[1]$} \\
\hline PA23-443 & Phz $^{-}$Rif $^{R}$ ptrA::Tn5-OT182 genomic fusion & This study \\
\hline \multicolumn{3}{|l|}{ E. coli } \\
\hline $\mathrm{DH} 5 \mathrm{a}$ & supE44 $\Delta$ lacU169 ( $\varphi 80$ lacZUM15) hsdR17 recA1 endA1 gyrA96 thi-1 relA1 & Gibco \\
\hline SM10 & Mobilizing strain; RP4 tra genes integrated in chromosome; $\mathrm{Km}^{\mathrm{R}} \mathrm{Tc}^{\mathrm{R}}$ & [33] \\
\hline \multicolumn{3}{|l|}{ Plasmids } \\
\hline рОT182 & pSUP102(GM)::Tn5-OT182 $\mathrm{Cm}^{R} \mathrm{Gm}^{R} \mathrm{Amp}^{R} \mathrm{Tc}^{\mathrm{R}}$ & [34] \\
\hline pOT182-443 (Xhol) & pOT182 containing ptrA::Tn5-OT182 genomic fusion & This study \\
\hline pCR2.1TOPO & Cloning vector for PCR products & Invitrogen \\
\hline pUCP22 & Broad-host-range vector; IncP OriT, $\mathrm{Amp}^{\mathrm{R}} \mathrm{Gm}^{\mathrm{R}}$ & [35] \\
\hline pUCP22-ptrA & pUCP22 containing ptrA from P. chlororaphis PA23 & This study \\
\hline \multicolumn{3}{|l|}{ Primers } \\
\hline ptrA-F & 5'-gggaaccggcttatagcca-3' & This study \\
\hline ptrA-R & $5^{\prime}$-atccagttgctggagcgtatt-3' & This study \\
\hline TNP5-FORWARD & 5'-accatttcaacggggtctcac-3' & [4] \\
\hline TNP5-REVERSE & 5'-tgactccatgtgacctccta-3' & [4] \\
\hline Tn5-ON82 & 5'-gatcctggaaaacgggaaagg-3' & [4] \\
\hline Tn5-OT182 right & 5'-atgttaggaggtcacatg-3' & {$[4]$} \\
\hline
\end{tabular}

potato dextrose agar (PDA; Difco). As required, media were supplemented with the following antibiotics: tetracycline (Tc; $15 \mu \mathrm{g} / \mathrm{mL})$, gentamicin (Gm; $15 \mu \mathrm{g} / \mathrm{mL}$ ), ampicillin (Amp; $100 \mu \mathrm{g} / \mathrm{mL}$ ) for $E$. coli, and rifampicin (Rif; $25 \mu \mathrm{g} / \mathrm{mL})$, Tc $(15$ or $100 \mu \mathrm{g} / \mathrm{mL}), \mathrm{Gm}(25 \mu \mathrm{g} / \mathrm{mL})$, piperacillin (30 or $500 \mu \mathrm{g} / \mathrm{mL}$ ) for $P$. chlororaphis. All antibiotics were obtained from Research Products International Corp. (Mt. Prospect, Illinois).

\section{PCR}

Polymerase Chain Reaction (PCR) was performed under standard conditions as suggested by Invitrogen Life Technologies data sheets supplied with their Taq polymerase.

\section{Nucleic acid manipulation}

Cloning, purification, electrophoresis, and other manipulations of nucleic acid fragments and constructs were performed using standard techniques [36]. To clone the PA23 ptrA gene, oligonucleotide primers ptrA-F and ptrA-R were used to amplify a $2.2-\mathrm{kb}$ product which was cloned into vector pCR2.1-TOPO following manufacturer's instructions. The 2.2-kb $p t r A$ insert was then excised with $\mathrm{XbaI}$ and $\mathrm{BamHI}$ and cloned into the same sites of pUCP22, generating pUCP22-ptrA.

\section{Tn5-OT182 transposon mutagenesis}

Bacterial conjugations were performed to introduce Tn5-OT182 into P. chlororaphis PA23 by biparental mating following the method of Lewenza et al., [37]. For each mating, 5-10 $\mathrm{Tc}^{\mathrm{R}}$ colonies were screened by PCR to ensure that transconjugants contained a Tn5 insertion using TNP5-FORWARD and TNP5-REVERSE primers. To determine the site of Tn5-OT182 insertion, rescue cloning was performed following previously described methods [37].

\section{Sequence analysis and nucleotide accession number}

Plasmids isolated from $\mathrm{Tc}^{\mathrm{R}}$ XhoI clones were sent for sequencing using oligonucleotide primer Tn5-ON82, which anneals to the $5^{\prime}$ end of Tn5-OT182. BamHI or ClaI rescue plasmids were sequenced using primer Tn5OT182 right, which anneals to the 3 ' end of the transposon. All sequencing was performed at the University of Calgary Core DNA Services facility. Sequences were analyzed using BLASTn and BLASTx databases (http:// blast.ncbi.nlm.nih.gov/Blast.cgi?CMD=Web\&PAGE_TYPE= BlastHome). The GenBank accession number for the $P$. chlororaphis PA23 ptrA gene sequence is EF054873.

\section{Antifungal assays}

Radial diffusion assays to assess fungal inhibition against $S$. sclerotiorum in vitro were performed with wild-type PA23, mutant PA23-443 and PA23-443 harboring the ptrA gene in trans according to previously described methods [4]. Five replicates were analyzed for each strain and assays were repeated three times. 


\section{Proteomic analysis}

Wild-type PA23 and mutant PA23-443 cells were grown as duplicate samples. At the point when cultures were just entering stationary phase $\left(\mathrm{OD}_{600}=1.2\right)$, they were centrifuged at $10,000 \times \mathrm{g}$ for 10 minutes at $4^{\circ} \mathrm{C}$, and pellets were washed three times in PBS buffer and frozen at $-80^{\circ} \mathrm{C}$. Further sample preparation and iTRAQ labelling was carried out at the Manitoba Centre for Proteomics and Systems Biology. Briefly, $100 \mu \mathrm{g}$ protein samples were mixed with $100 \mathrm{mM}$ ammonium bicarbonate, reduced with $10 \mathrm{mM}$ dithiothreitol (DTT) and incubated at $56^{\circ} \mathrm{C}$ for $40 \mathrm{~min}$. Samples were then alkylated with $50 \mathrm{mM}$ iodoacetamide (IAA) for $30 \mathrm{~min}$ at room temperature in the dark. Addition of $17 \mathrm{mM}$ DTT was used to quench excess IAA, and proteins were digested with sequencing-grade trypsin (Promega, Madison, WI, USA) overnight. Dried samples were then desalted with $0.1 \%$ trifluoroacetic acid and subjected to two-dimensional high-performance liquid chromatography (2D-HPLC)-mass spectrometry (MS) according to previously described methods [38].

\section{Database search and protein identification}

2D-HPLC-MS/MS spectra data from three independent runs were analyzed using ProteinPilot (v2.0.1, Applied Biosystems/MDS Sciex, Concord, ON, Canada) which employs the Paragon ${ }^{\mathrm{Tm}}$ algorithm. Searches were performed against the $P$. chlororaphis strain gp72 reference genome. Reporter ion iTRAQ tags were labelled as follows: tags 114 and 115 to replicates of wild-type PA23 grown to early stationary phase, and tags 116 and 117 to replicates of mutant PA23-443 grown to early stationary phase. Results were reported as Z-scores, the $\log 2$ of the ratio among replicates $\left(\mathrm{Z} 0=\operatorname{tag}_{116} / \operatorname{tag}_{114} ; \mathrm{Z1}=\operatorname{tag}_{117} /\right.$ $\left.\operatorname{tag}_{115} ; Z 2=\operatorname{tag}_{115} / \operatorname{tag}_{114} ; Z 3=\operatorname{tag}_{117} / \operatorname{tag}_{116}\right)$. Peptide Zscores values were histogrammed $(\mathrm{Z} 0, \mathrm{Z1})$ to determine the overall population distribution. Further statistical analysis was performed according to the methods outlined in Rydzak et al., [38]. Briefly, $\mathrm{V}_{\text {diff }}$ scores were assigned to allow the determination of statistical significance of protein expression ratios between both the wild-type and mutant samples while also taking into account the variation between biological replicates. Plotted Z-scores were transformed into vector values, allowing comparison between points $(\mathrm{Z} 0, \mathrm{Z1})$ and $(\mathrm{Z} 2, \mathrm{Z} 3)$. Differences between magnitudes of the vector values from the origin to points $(\mathrm{Z} 0, \mathrm{Z} 1)$ and $(\mathrm{Z} 2, \mathrm{Z} 3)$ were adjusted to the widths of the peptide population distributions. Direction of the vector values (+or -) were assigned based on the angle subtended by the vector value from the origin to point $(\mathrm{Z} 0, \mathrm{Z} 1)$. $\mathrm{A} \mathrm{V}_{\text {diff }}$ value greater than or equal to +1.65 and less than or equal to -1.65 corresponds to proteins expressed in the upper or lower $10 \%$ of the population distribution [38]. Functional classification of proteins was carried out using the Integrated Microbial
Genomes (IMG) database (http://img.jgi.doe.gov/cgi-bin/ w/main.cgi) against the $P$. chlororaphis strain gp72 genome.

\section{Growth curve analysis}

Cultures of wild-type PA23 and mutant PA23-443 were inoculated at a starting optical density (OD) 600 of 0.01 and grown in M9 minimal media ( $1 \mathrm{mM} \mathrm{MgSO}_{4} ; 0.2 \%$ glucose). $\mathrm{OD}_{600}$ readings were taken at 1 hour, 5 hours and 9 hours, followed by readings every 2 hours until 27 hours of growth. Triplicate samples were analyzed.

\section{Chitinase assay}

PA23 and derivative strains were assayed for chitinase production during early stationary and late stationary phases following the methods outlined by Wirth and Wolf [39]. Briefly, cultures were grown to the desired growth phase in M9 minimal media (1 $\mathrm{mM} \mathrm{MgSO}_{4}$; $0.2 \%$ glucose) and $250 \mu \mathrm{L}$ aliquots of each of cell-free supernatant, 0.1 M NaOAc, pH 5.2 and carboxymethylchitin-Remazol brilliant violet aqueous solution (Loewe Biochemica, Germany) were incubated for 1 hour at $37^{\circ} \mathrm{C}$. The reaction was stopped by the addition of $250 \mu \mathrm{L} 1 \mathrm{M}$ HCL. Reaction mixtures were cooled on ice for $10 \mathrm{~min}$ and spun at $20,000 \times \mathrm{g}$ for $10 \mathrm{~min}$, and the absorbances at $550 \mathrm{~nm}$ were recorded. Each experiment was performed in triplicate.

\section{Flagellar motility analysis}

Flagellar (swimming) was monitored according to Poritsanos et al., [4]. Strains were grown overnight in M9 minimal media ( $1 \mathrm{mM} \mathrm{MgSO}_{4} ; 0.2 \%$ glucose) and $5 \mu \mathrm{L}$ was inoculated into the center of $0.3 \%$ M9 agar plates. Four replicates were analyzed and the experiment repeated three times.

\section{Phenazine analysis}

Overnight cultures in M9 minimal media (1 mM MgSO 4 ; $0.2 \%$ glucose) were subjected to phenazine extraction and quantification by UV-visible light spectroscopy at $367 \mathrm{~nm}$ and $490 \mathrm{~nm}$ for PCA and 2-OH-PHZ, respectively [5]. Phenazine analysis was performed in triplicate.

\section{Siderophore analysis}

Overnight cultures grown in M9 minimal media (1 mM $\mathrm{MgSO}_{4} ; 0.2 \%$ glucose) were spotted onto CAS media according to the methods outlined in Schwyn and Neilands [40] to analyze siderophore production.

\section{Pyrrolnitrin analysis}

Production of the antibiotic PRN was quanitified according to the methods outlined in [5]. Briefly, $20 \mathrm{~mL}$ cultures of PA23 and its derivatives were grown for 5 days in M9 minimal media and PRN was extracted with an equal 
volume of ethyl acetate. Before extraction, toluene $(5 \mathrm{~mL})$ was added to each sample as an internal control. Toluene and PRN UV absorption maxima were recorded at $225 \mathrm{~nm}$ with a Varian 335 diode array detector. PRN peaks were detected at 4.7 mins. Samples were analyzed in duplicate.

\section{Statistical analysis}

All statistical analysis was performed using unpaired Students's $t$ test.

\section{Availability of supporting data}

The data sets supporting the results of this article are included within the article.

\section{Abbreviations}

LTTR: LysR-type transcriptional regulator; PtrA: Pseudomonas transcriptional regulator A; iTRAQ: Isobaric tag for relative and absolute quantitation; PCA: Phenazine 1-carboxylic acid; 2-OH-PHZ: 2-hydroxyphenazine; RBS: Ribosome-binding site; QS: Quorum sensing; COG: Clusters of orthologous groups; CAS: Chrome Azurol S; DTT: Dithriothreitol;

IAA: iodoacetamide; 2D-HPLC: Two-dimensional high-performance liquid chromatography; MS: Mass spectrometry; $V_{\text {diff: }}$ Vector difference; OD: Optical density.

\section{Competing interests}

The following patent has been filed:

ptrA gene and uses therefore. Inventors: de Kievit, T., Selin, C., and Fernando, D.

US patent application \# US 12/446,745, filed Feb. 1, 2010 (status: patent pending).

\section{Authors' contributions}

NK, WGDF, MB and TdK conceived and designed the study. NK drafted the manuscript with input from TdK. NK prepared samples for proteomic analysis; NK, CS and KD performed the phenotypic characterization of the ptrA mutant. VS assisted with the proteomic analysis. All authors read and approved the final manuscript.

\section{Acknowledgements}

The authors gratefully acknowledge financial support for this work through grants awarded to T.R. de K., W.G.D.F. and M.F.B. from the Natural Sciences and Engineering Research Council (NSERC) Discovery Grants Program and the Agri-Food Research and Development Initiative (ARDI). We thank T. Verbeke, R. Sparling, and Dr. D. Court for helpful discussions and S. Liban for critical review of the manuscript. We are indebted to the Manitoba Centre for Proteomics and Systems Biology for the proteomic analyses.

\section{Author details}

'Department of Microbiology, University of Manitoba, R3T 2N2 Winnipeg, MB, Canada. ${ }^{2}$ Department of Physics and Astronomy, University of Manitoba, R3T 2 N2 Winnipeg, MB, Canada. ${ }^{3}$ Department of Plant Science, University of Manitoba, R3T 2 N2 Winnipeg, MB, Canada. ${ }^{4}$ Department of Biological Science, University of Manitoba, R3T 2 N2 Winnipeg, MB, Canada.

Received: 16 December 2013 Accepted: 9 April 2014

Published: 17 April 2014

\section{References}

1. Savchuk SC, Fernando WGD: Effect of timing of application and population dynamics on the degree of biological control of Sclerotinia sclerotiorum by bacterial antagonists. FEMS Microbiol Ecol 2004, 49:379-388.

2. Zhang Y: Biocontrol of Sclerotinia stem rot of canola by bacterial antagonists and study of biocontrol mechanisms involved. In M.Sc. Thesis. Winnipeg: University of Manitoba; 2004.

3. Zhang Y, Fernando WGD, de Kievit T, Berry C, Daayf F, Paulitz TC: Detection of antibiotic-related genes from bacterial biocontrol agents using polymerase chain reaction. Can J Microbiol 2006, 52:476-481.
4. Poritsanos N, Selin C, Fernando WGD, Nakkeeran S, de Kievit TR: A GacS deficiency does not affect Pseudomonas chlororaphis PA23 fitness when growing on canola, in aged batch culture or as a biofilm. Can J Microbiol 2006, 52(12):1177-1188.

5. Selin C, Habibian R, Poritsanos N, Athukorala SN, Fernando D, de Kievit TR: Phenazines are not essential for Pseudomonas chlororaphis PA23 biocontrol of Sclerotinia sclerotiorum, but do play a role in biofilm formation. FEMS Microbiol Ecol 2010, 7:73-83.

6. Cook RJ: Making greater use of introduced microorganisms for biological control of plant pathogens. Annu Rev Phytopathol 1993, 31:53-80.

7. Haas D, Keel C: Regulation of antibiotic production in root-colonizing Pseudomonas spp. and relevance for biocontrol of plant disease. Annual Rev Phytopathol 2003, 41:117-153.

8. Walsh UF, Morrissey JP, O'Gara F: Pseudomonas for biocontrol of phytopathogens: from functional genomics to commercial exploitation. Curr Opin Biotechnol 2001, 12:289-295.

9. Heeb S, Haas D: Regulatory roles of the GacS/GacA two-component system in plant-associated and other Gram-negative bacteria. Mol Plant-Microbe Interact 2001, 14:1351-1363.

10. Lapouge K, Schubert M, Allain F, Haas D: Gac/Rsm signal transduction pathway of $\gamma$-proteobacteria: from RNA recognition to regulation of social behaviour. Mol Microbiol 2008, 67(2):241-253.

11. Selin C, Fernando WGD, de Kievit T: The Phzl-PhzR quorum-sensing system is required for pyrrolnitrin and phenazine production, and exhibits crossregulation with RpoS in Pseudomonas chlororaphis PA23. Microbiol 2012, 158:896-907.

12. Manuel J, Selin C, Fernando WGD, de Kievit T: Stringent response mutants of Pseudomonas chlororaphis PA23 exhibits enhanced antifungal activity against Sclerotinia sclerotiorum in vitro. Microbiol 2012, 158:207-216.

13. Selin C, Manuel J, Fernando WGD, de Kievit T: Expression of the Pseudomonas chlororaphis strain PA23 Rsm system is under control of GacA, RpoS, PsrA, quorum sensing and the stringent response. Biol Control 2014, 69:24-33.

14. Maddocks E, Oyston P: Structure and function of the LysR-type transcriptional regulator (LTTR) family proteins. Microbiol 2008, 154:3609-3623.

15. Schell MA: Molecular biology of the LysR family of transcriptional regulators. Ann Rev Microbiol 1993, 47:597-626.

16. Müller FH, Bandeiras TM, Urich T, Teixeira M, Gomes CM, Kletzin A: Coupling of the pathway of sulphur oxidation to dioxygen reduction: characterization of a novel membrane-bound thiosulphate:quinone oxidoreductase. Mol Microbiol 2004, 53(4):1147-1160.

17. Jornvall H, Hoog JO, Persson B: SDR and MDR: completed genome sequences show these protein families to be large, of old origin, and of complex nature. FEBS Lett 1999, 445(2-3):261-264

18. Windsor GL, Lam DK, Fleming L, Lo R, Whiteside MD, Yu NY, Hancock RE, Brinkman FS: Pseudomonas genome database: improved comparative analysis and population genomics capability for pseudomonas genomes. Nucleic Acids Res 2011, 39:D596-D600.

19. Shen $X$, Chen M, Hu H, Wang W, Peng H, Xu P, Zhang X: Genome sequence of Pseudomonas chlororaphis GP72, a root-colonizing biocontrol strain. J Bacteriol 2012, 194:1269-1270.

20. Mentel M, Ahuja EG, Mavrodi DV, Breinbauer R, Thomashow LS, Blankenfeldt W: Of two make one: the biosynthesis of phenazines. Chem Bio Chem 2009, 10:2295-2304.

21. Pierson LS, Gaffney T, Lam F, Gong F: Molecular analysis of genes encoding phenazine biosynthesis in the biological control bacterium Pseudomonas aureofaciens 30-84. FEMS Microbiol Lett 1995, 134:299-307.

22. Mavrodi DV, Bonsall RF, Delaney SM, Soule MJ, Phillips G, Thomashow LS: Functional analysis of genes for biosynthesis of pyocyanin and phenazine-1-carboxamide from Pseudomonas aeruginosa PAO1. J Bacteriol 2001, 183(21):6454-6465.

23. Delaney SM, Mavrodi DV, Bonsall RF, Thomashow LS: phzO, a gene for biosynthesis of 2-hydrolyated phenazine compounds in Pseudomonas aureofaciens 30-84. J Bacteriol 2001, 183:318-27.

24. Chin-A-Woeng TFC, Thomas-Oates JE, Lugtenberg BJJ, Bloemberg GV: Introduction of the phzH gene of Pseudomonas chlororaphis PCL1391 extends the range of biocontrol ability of phenazine-1-carboxylic acidproducing Pseudomonas spp. strains. Mol Plant-Microbe Interact 2001, 14(8):1006-1015.

25. Huang L, Chen M-M, Wang W, Hu H-B, Peng H-S, Xu Y-Q, Zhang X-H: Enhanced production of 2-hydroxyphenazine in Pseudomonas chlororaphis gp72. Appl Microbiol Biotechnol 2010, 89(1):169-177. 
26. Suzuki K, Uchiyama T, Suzuki M, Nikaidou N, Regue M, Watanabe T: LysRtype transcriptional regulator ChiR is essential for production of all chitinases and a chitin-binding protein, CBP21, in Serratia marcescens 2170. Biosci Biotechnol Biochem 2001, 65(2):338-347.

27. Kay E, Humair B, Denervaud V, Riedel K, Spahr S, Eberl L, Valverde C, Haas D: Two GacA-dependent small RNAs modulate the quorum-sensing response in Pseudomonas aeruginosa. J Bacteriol 2006, 188(16):6026-6033.

28. Lecompte O, Ripp R, Thierry J-C, Moras D, Poch O: Comparative analysis of ribosomal proteins in complete genomes: an example of reductive evolution at the domain scale. Nucl Acids Res 2002, 30(24):5382-5390

29. Driscoll WW, Pepper JW, Pierson LS, Pierson EA: Spontaneous Gac mutants of Pseudomonas biological control strains: cheaters or mutualists? Appl Environ Microbiol 2011, 77(20):7227-7235.

30. Wei Q, Le Minh PN, Dotsch A, Hildebrand F, Panmanee W, Elfarash A, Schultz S, Plaisance S, Charlier D, Hassett D, Haussler S, Cornelis P: Global regulation of gene expression by OxyR in an important human opportunistic pathogen. Nucl Acids Res 2012, 40(10):4320-4333.

31. Vinckx T, Wei Q, Matthijs S, Cornelis P: The Pseudomonas aeruginosa oxidative stress regulator OxyR influences production of pyocyanin and rhamnolipids: protective role of pyocyanin. Microbiol 2010, 156:768-686.

32. Hammer PE, Burd W, Hill DS, Ligon JM, van Pée K: Conservation of the pyrrolnitrin biosynthetic gene cluster among six pyrrolnitrin-producing strains. FEMS Microbiol Lett 1999, 180(1):39-44.

33. Simon R, Priefer U, Pühler A: A broad-host-range mobilization system for in vivo genetic engineering: transposon mutagenesis in gram negative bacteria. Bio/Technology 1983, 1:784-791.

34. Merriman TR, Lamont IL: Construction and use of a self-cloning promoter probe vector for gram-negative bacteria. Gene 1993, 126:17-23.

35. West SE, Schweizer HP, Dall C, Sample AK, Runyen-Janecky L: Construction of improved Escherichia-Pseudomonas shuttle vectors derived from pUC18/19 and sequence of the region required for their replication in Pseudomonas aeruginosa. Gene 1994, 148:81-86.

36. Sambrook J, Fritsch EF, Maniatis T: Molecular Cloning: a Laboratory Manual. 2nd edition. Cold Spring Harbor, N.Y.: Cold Spring Harbor Laboratory; 1989.

37. Lewenza S, Conway B, Greenberg EP, Sokol PA: Quorum sensing in Burkholderia cepacia: identification of LuxRI homogs CepRI. J Bacteriol 1999, 181:748-756

38. Rydzak T, McQueen PD, Krokhin OV, Spicer V, Ezzati P, Dwivedi RC, Shamshurin D, Levin DB, Wilkins JA, Sparling R: Proteomic analysis of Clostridium thermocellum core metabolism: relative protein expression profiles and growth phase-dependent changes in protein expression. BMC Microbiol 2012, 12:214-232.

39. Wirth SJ, Wolf GA: Dye-labelled substrates for the assay and detection of chitinase and lysozyme activity. J Microbiol Methods 1990, 12:197-205.

40. Schwyn B, Neilands JB: Universal chemical assay for the detection and determination of siderophores. Anal Biochem 1987, 160(1):47-56.

doi:10.1186/1471-2180-14-94

Cite this article as: Klaponski et al.: The requirement for the LysR-type regulator PtrA for Pseudomonas chlororaphis PA23 biocontrol revealed through proteomic and phenotypic analysis. BMC Microbiology 2014 14:94

\section{Submit your next manuscript to BioMed Central and take full advantage of:}

- Convenient online submission

- Thorough peer review

- No space constraints or color figure charges

- Immediate publication on acceptance

- Inclusion in PubMed, CAS, Scopus and Google Scholar

- Research which is freely available for redistribution 